\title{
The study for installing noise barrier on highway route no.9
}

\author{
Chaddanai Jiradecha ${ }^{1}$ and Pruethipong Singhatiraj ${ }^{2, a}$ \\ ${ }^{1}$ Department of Environmental Engineering, Kasetsart University, Thailand \\ ${ }^{2}$ Department of Highways, Ministry of Transports, Thailand
}

\begin{abstract}
Highway Route No. 9 is a Bangkok bypass motorway that aims to alleviate traffic congestion in greater Bangkok areas. Presently, it is found a rapid expansion of new communities residing along both side of Highway No. 9. To lessen the noise level, Department of Highways installed the noise barrier on the sensitive locations. However, people from communities living on both sides of highway still demand some additional noise pollution improvement. To improve the efficiency of using noise barriers and to promote environmental and social quality for the people on the sensitive communities along the highway route, the Department of Highways, therefore, designs a new technique for installing noise barrier on the sensitive areas, i.e. education institutions, temple, residential area. In addition, the mathematic model is applied to 12 selected locations of sensitive areas for monitoring the effectiveness of the new installation technique. The mathematic model is used for predict the future noise level after installation of noise barrier in year 2037. The results confirm that the appropriate height and width of noise barrier can improve the comfortable of the people on the sensitive area.
\end{abstract}

\section{Introduction}

Highway No.9 (Bangna - Bang Pa In) is a motorway network system starting at Wang Noi District, Ayutthaya Province and ending at Bang Phli District, Samut Prakarn Province. It is a Bangkok bypass road that aims to alleviate traffic problem in greater Bangkok areas. The project distance has 65.325 $\mathrm{km}$. length. The alignment of the network is shown in Figure 1. From the air photo map shown in Figure 1, Most of the land currently used on the area around motorway route no.9 is for the purpose of agriculture products, mainly on rice planting. However, based on the analysis of land use data during 14 years (1999-2013), it shows that there is a trend of land use changing from agricultural purpose to be residential purpose. The percentage of rice field dropped from $43 \%$ in 1999 to $30 \%$ in 2013 while the percentage of residential area rose from $12 \%$ in 1999 to $30 \%$ in 2013

As discussed above, it is found a rapid expansion of new residential community residing along the both side of Highway route no. 9. The previous study on the noise impact on the communities surrounding Highway 9 discloses that the noise level did not exceed the noise standard. Even though the noise level is within the standard, the Department of Highways installs the noise barrier to lessen traffic noise to the community. Nevertheless, People from communities living on both sides of the highway need some improvement on the noise pollution. So, a new installation technique of noise barrier is carry out in this study to reduce the traffic noise.

\footnotetext{
${ }^{\mathrm{a}}$ Corresponding author : pruethi@gmail.com
} 


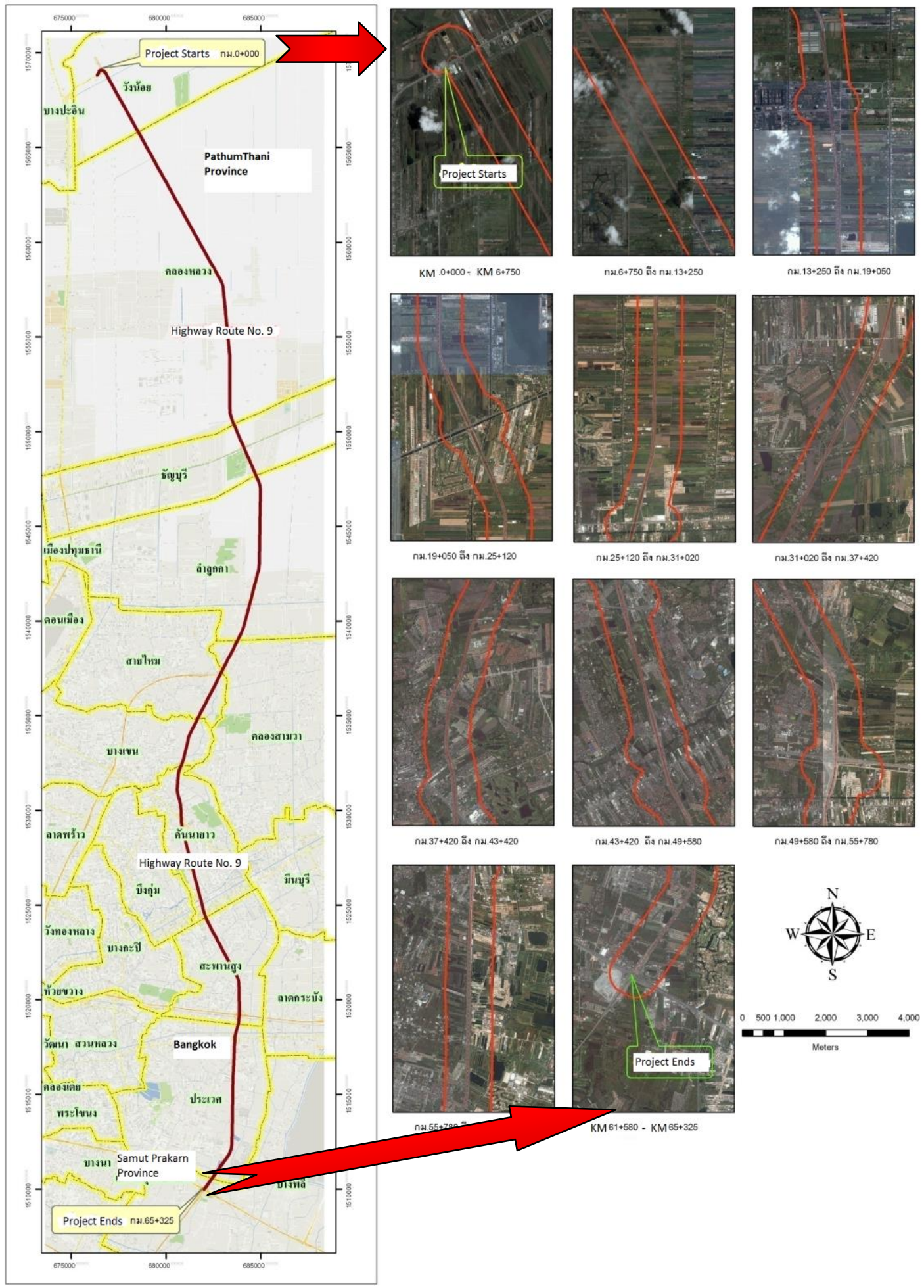

Figure 1. Project Alignment 


\section{Site investigation}

\subsection{Land uses}

Most of the land currently used on the area around motorway route no.9 is for the purpose of agriculture products, mainly on rice. However, based on the analysis of land use data during 14 years (1999-2013), it shows that there is a trend of land use changing from agricultural purpose to be residential purpose. The percentage of rice field dropped from $43 \%$ in 1999 to $30 \%$ in 2013 while the percentage of residential area rose from $12 \%$ in 1999 to $30 \%$ in 2013

\subsection{Sensitive areas}

Based on an investigation on the area within 500 meters from each side of the road throughout the project, it is found that there are 30 sensitive areas that may be affected by traffic noise. The 30 sensitive areas comprise of 8 educational institutions, 10 temples, 11 communities and 1 hospital.

\subsection{Present condition of the existing noise barriers}

Previously, there is some noise pollution complaints from the people living closed to the highway route no.9. To lessen the noise issue, the department of highways installed noise barriers on such area. So far, the Department of Highways installed noise barriers in 11 areas from 30 sensitive areas stated earlier. However, to fix systematically traffic noise problem, the detailed study of action plan for noise pollution was recognized by the Department of Highways and then carried out in this study. Presently, Glassfiber Reinforced Concrete (GRC) type and Fiber Reinforced Plastic (FRP) type are typically used by the Department of Highways.

\subsection{Geological data}

To design the foundation of noise barrier, the geological data on the project area is investigated. The soil characteristics along Highway No. 9 (Bangna - Bang Pa In) are mostly clay and sand and can be classified as very soft to soft clay. The thickness of the clay is about 4-5 meters depth in the first 7 kilometers and in the range of 5-15 meters from KM. 7 until the end of the project.

\subsection{Acceptable noise level}

Table 1. Acceptable Noise Level

\begin{tabular}{|c|c|c|}
\hline \multirow{2}{*}{ Type of Land Use } & \multicolumn{2}{|c|}{ Noise Level (dBA) } \\
\cline { 2 - 3 } & Day Time (06:00-22.00) & Night Time (22:00-06:00) \\
\hline Sensitive Areas (School Hospital Temple) & 55 & 50 \\
\hline Residential Area & 60 & 55 \\
\hline Resident in Commercial Area & 65 & 55 \\
\hline Entertainment Area and Agriculture & 65 & 65 \\
\hline Commercial Area & 70 & 60 \\
\hline Industrial Area & 70 & 65 \\
\hline
\end{tabular}

From various national standards, the acceptable noise level is normally set by the characteristic of land using. The noise level for each type of land using is mostly classified as daytime level (06:00-22:00 or $07: 00-22: 00)$ and night time level (22:00-06:00 or 22:00-07:00). So, in this study, the optimum values of noise level for each type of land use are classified as daytime and night time. Then, the public participation on the optimum values of acceptable noise level is conducted. This is done by interviewing people that are experimented on the noise comfortable test in 10 -stations along the 
motorway route at different periods of time to determine the acceptable noise level. Then, the public hearing from various state agency and university's noise experts on the acceptable noise level are performed.

\section{Traffic noise prediction model}

The present condition of sound level and traffic volume are the key information necessary for developing traffic noise prediction model.

\subsection{Present sound level}

Based on the results of the sound level monitoring at 10 stations along the project route, the Leq $24 \mathrm{hr}$ (average 24 hours A weighted Equivalent Continuous Sound Level) is higher than the standard sound level set by the National Environmental Board's Notification No. 15 (1997), which is set at 70 dBA. Moreover, the noise level in weekday is higher than the weekend. As a result, the average noise level in weekday is investigated for developing noise prediction model.

\subsection{Traffic analysis}

As stated earlier, the measured sound levels and their traffic volume are essential to develop traffic noise model. The two main purposes of the traffic data collection and traffic analysis are:

(a) to input to the traffic noise mathematical model (SoundPlan) for predicting sound level and then using sound level measured in section 3.1 to calibrate the predicted noise level result.

(b) to forecast future traffic volume in year 2037 and then using these future traffic volumes to predict the future noise level by using the developed mathematic model from (a).

From the investigation, it is noted that the average traffic volume in weekday is more than that in weekend and more than the annual average traffic volume (AADT). As a result, the average traffic volume in weekday is used in the mathematical model for noise level analysis. Based on an investigation on the area within 500 meters from each side of the road throughout the project, it is found that there are 30 sensitive areas that may be affected by traffic noise. The 30 sensitive areas comprise of 8 educational institutions, 10 temples, 11 communities and 1 hospital.

\subsection{Future noise level}

From the model, it is shown that the traffic volume increases at the average rate of 3.222 percent per annum. This leads the rate of noise level growth 0.153 percent per year. It can be summarized that increasing in traffic volume results slightly on noise level. Even though, the predicted future noise level on the project area increased slightly, the present noise volume exceeds the appropriate noise level. So, the application of noise barrier is essential on the project area to lessen noise pollution.

\section{Noise barrier installation study}

Presently, the noise barrier are made from 8 types of materials: 1) Concrete Products 2) Metals 3) Plastics 4) Recycled Materials 5) Fiberglass Reinforced Plastic (FRP) 6) Glass 7) Acrylic and 8) Wood. This study is aimed to investigate the most suitable type of noise barrier for current road conditions. The criteria for study are listed as follows:

(a) Noise barriers must be a sound-proof and suited with the highway works.

(b) Noise barriers must be certified internationally.

(c) Noise barriers should be appropriate for Thai Environment.

(d) Noise barriers should be available in Thailand 
(e) Noise barriers must be consistent with local restrictions and the need of people in the community.

(f) Physical Property

(g) Easy to Erection

(h) Ease of Maintenance

(i) Price

(j) Safety

Based on the criteria set above, the most appropriate of noise barrier is Acrylic type and then follow by Fiberglass Reinforced Plastic (FRP), Glass Fiber Reinforced Cement (GRC), and Metal type, subsequently. However, the additional concepts were applied for the selection of noise barrier in this study.

(a) In area of pleasing roadside view, the transparent acrylic noise barrier should be selected.

(b) In area of displeasing roadside view, the non-transparent acrylic noise barrier should be selected.

(c) In area of high-rise buildings, the FRP noise barrier should be selected to absorb the reflection noise.

Due to the fact that most of the land use characteristic along the project area is agricultural and residential purpose. So, the acrylic type noise barrier is preferred for this study.

\section{Pilot areas}

To prove the effective of the above concept, some sensitive areas within a 100 -meter from the roadway along the motorways route no.9 are selected as pilot areas. The SoundPlan program is used to predict the noise level. The pilot areas comprise of 12 locations, i.e. 6 education institutes, 5 residential areas, and 1 temple.

The following assumptions are used for the study.

(a) Acrylic type noise barrier is used for erection.

(b) SoundPlan Program is used for the design.

(c) The maximum height of noise barrier is $10 \mathrm{~m}$.

(d) The target is to reduce noise level in year 2037 at least $10 \mathrm{dBs}$ in each pilot locations, guided by The Federal Highway Authority (FHWA).

Prior to the application of new noise barrier, the noise level on all the pilot areas exceed the acceptable level. However, after the application of new noise barriers, 7 areas are within the acceptable level but 5 areas still beyond the satisfactory level. This is because these 5 areas are quite adjacent to the road, frontage road, or the zone closed to the major traffic intersections which are the source of traffic noise. However, the traffic volume decreases with increasing distance from the road.

Moreover, the results from SoundPlan program indicate that the new noise barrier can absorb noise level by average about of 10.7 and 10.9 decibels, in daytime and night time, respectively. The details are list on Table2.

Table 2. Noise Level Analysis Using SoundPlan (After Installation of Noise Barrier)

\begin{tabular}{|c|c|c|c|c|c|c|c|c|c|c|c|}
\hline \multirow[t]{2}{*}{ No. } & \multirow[t]{2}{*}{$\begin{array}{c}\text { Sensitive } \\
\text { Area }\end{array}$} & \multirow[t]{2}{*}{$\begin{array}{l}\text { Length } \\
\text { (meter) }\end{array}$} & \multirow[t]{2}{*}{$\begin{array}{l}\text { Height } \\
\text { (meter) }\end{array}$} & \multicolumn{2}{|c|}{$\begin{array}{c}\text { Acceptable } \\
\text { Noise Level } \\
(\mathrm{dBA})\end{array}$} & \multicolumn{2}{|c|}{$\begin{array}{c}\text { Before } \\
\text { Installed } \\
(\mathrm{dBA})\end{array}$} & \multicolumn{2}{|c|}{$\begin{array}{l}\text { After Installed } \\
\qquad(\mathrm{dBA})\end{array}$} & \multicolumn{2}{|c|}{$\begin{array}{c}\text { Noise level } \\
\text { Reduction } \\
(\mathrm{dBA})\end{array}$} \\
\hline & & & & Day & Night & Day & Night & Day & Night & Day & Night \\
\hline 1 & $\begin{array}{c}\text { Education } \\
\text { institute }\end{array}$ & 230 & 5 & 55 & 50 & 59.9 & 58.4 & 49.1 & 48.2 & -10.8 & -10.2 \\
\hline 2 & Residential area & 300 & 5 & 55 & 50 & 68.6 & 63.6 & 58.6 & 52.9 & -10.0 & -10.7 \\
\hline 3 & Temple & 870 & 4.5 & 55 & 50 & 70.4 & 67.7 & 57.9 & 54.8 & -12.5 & -12.9 \\
\hline 4 & $\begin{array}{l}\text { Education } \\
\text { institute }\end{array}$ & 235 & 5.5 & 55 & 50 & 75.5 & 69.9 & 64.6 & 59.5 & -10.9 & -10.4 \\
\hline 5 & Residential area & 880 & $5.5 / 5$ & 60 & 55 & 66.2 & 63.3 & 56 & 52.2 & -10.2 & -11.1 \\
\hline 6 & $\begin{array}{c}\text { Education } \\
\text { institute }\end{array}$ & 1,130 & 5 & 55 & 50 & 65.6 & 61.7 & 55.6 & 51.1 & -10.0 & -10.6 \\
\hline
\end{tabular}




\begin{tabular}{|c|c|c|c|c|c|c|c|c|c|c|c|}
\hline 7 & $\begin{array}{l}\text { Residential } \\
\text { Area }\end{array}$ & 560 & 4 & 60 & 55 & 69.5 & 64.1 & 59.5 & 54.8 & -10.0 & -9.3 \\
\hline 8 & $\begin{array}{l}\text { Residential } \\
\text { Area }\end{array}$ & 300 & 4 & 65 & 55 & 71.7 & 68.2 & 60.4 & 56.7 & -11.3 & -11.5 \\
\hline 9 & $\begin{array}{c}\text { Education } \\
\text { institute }\end{array}$ & 300 & 4 & 55 & 50 & 71.1 & 67.9 & 60.6 & 57 & -10.5 & -10.9 \\
\hline 10 & $\begin{array}{c}\text { Education } \\
\text { institute }\end{array}$ & 900 & 5 & 55 & 50 & 65.8 & 61.2 & 55.8 & 51.9 & -10.0 & -9.3 \\
\hline 11 & $\begin{array}{c}\text { Residential } \\
\text { Area }\end{array}$ & 300 & 4 & 65 & 55 & 68.4 & 62.9 & 57.8 & 52.4 & -10.6 & -10.5 \\
\hline 12 & $\begin{array}{c}\text { Education } \\
\text { institute }\end{array}$ & 300 & 5.5 & 55 & 50 & 77.3 & 71.8 & 67 & 61.7 & -10.3 & -10.1 \\
\hline
\end{tabular}

\section{Detailed design of noise barrier}

After the new noise barrier concept was verified by the mathematic model, the next step is to develop the detailed design of the noise barrier for erection.

(a) Acrylic Barrier. Acrylic type $12 \mathrm{~mm}$. thickness is used. There are 3 levels. The lower level is $1 \mathrm{~m} . \mathrm{x} 2 \mathrm{~m}$., blue color (Opacity 60\%). The middle level is $2 \mathrm{~m} . \mathrm{x} 2 \mathrm{~m}$., blue color (Opacity $85 \%)$. The top level is $1 \mathrm{~m} . \mathrm{x} 2 \mathrm{~m}$., Opacity $92 \%$. The vertical frame is WF $100 \times 100(17.2$ $\mathrm{Kg} / \mathrm{m}) @ 2$ meters. The horizontal frame is aluminum made.

(b) Main Structure. The wide flange $250 \times 125(29.6 \mathrm{Kg} / \mathrm{m})$ is used for the main structure to support 5 meter height noise barrier. These wide flanges are installed every 4 meters.

The detailed of this design is shown on Figure 2, 3 and 4.

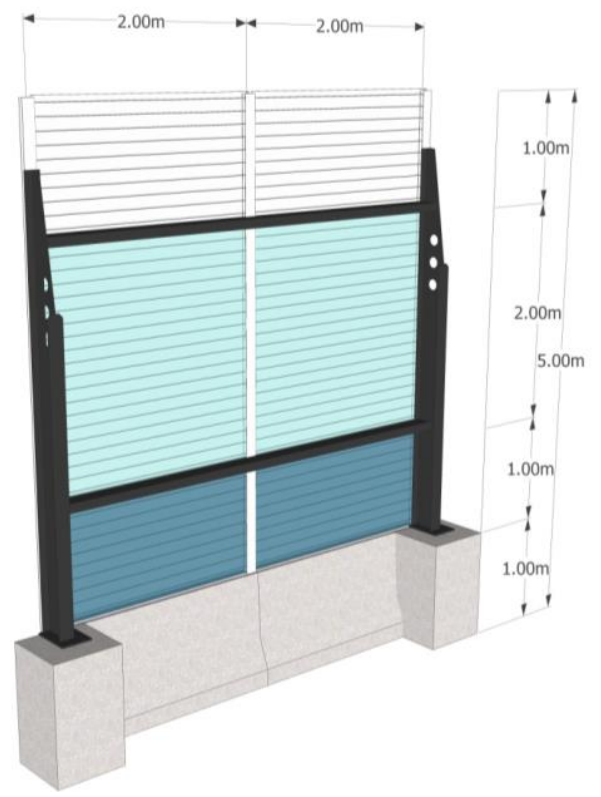

Figure 2. Noise Barrier on the Pilot Area 


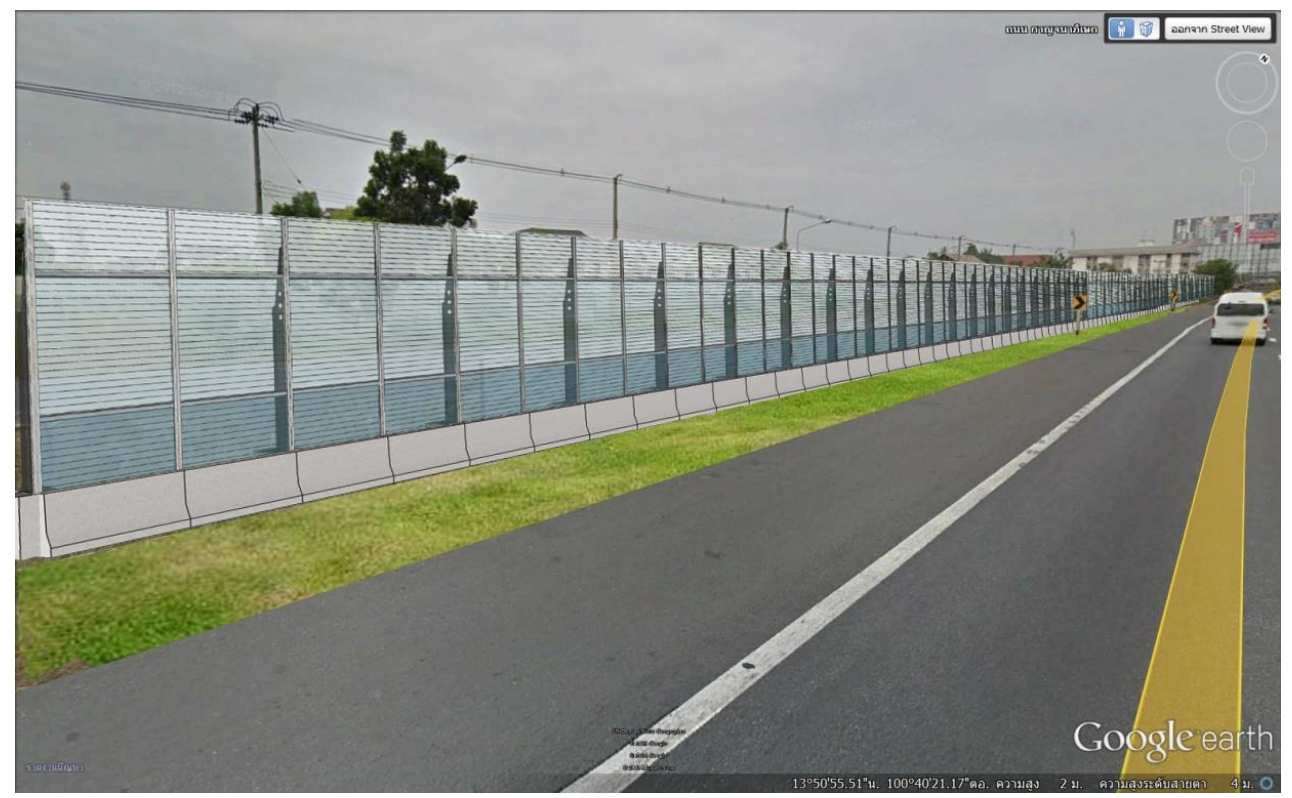

Figure 3. Noise Barrier on the Pilot Area

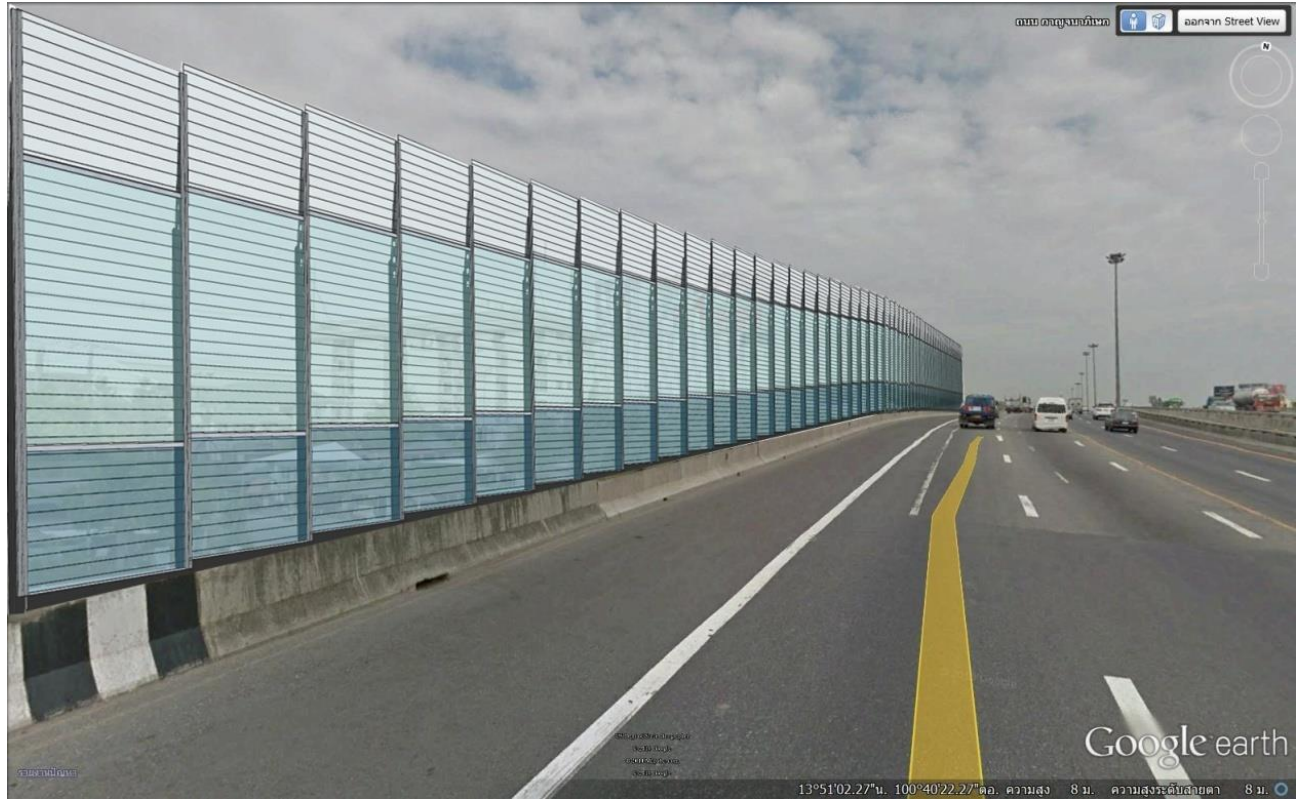

Figure 4. Noise Barrier on the Pilot Area

\section{Conclusion}

The traffic noise level is quite high at the locations closed to the roadway. This is because it closes to the source of traffic noise. The volume decreases as the distance from the roadway. The noise level increase at an average rate of 0.153 percent per year, while the traffic volume increases at an average rate of 3.222 percent per year. 
For the study of noise barrier products, acrylic type is the most appropriate to implement in the project when considering the following factors, e.g. physical properties, easy to erection, ease of maintenance, price, safety, etc.

There are 12 locations that are selected as the pilot areas for noise barrier installation. These 12 locations are select by three main factors: current noise pollution situation, traffic noise impact, and the value of investment. It can be concluded from the pilot areas that the appropriate height and width of noise barriers can improve the comfortable of the people on the sensitive area. However, the installation of merely noise barrier is not possible to reduce the traffic noise to the appropriate noise level. The following measures shall be applied to support.

(a) Changing road pavement surface by using more porous material. This will reduce the noise caused by friction between the tire and the road surface.

(b) Limiting speed.

(c) Intelligence Traffic Management System to reduce the conglomerate of the vehicle. Then, it will alleviate the accumulation of noise pollution caused from the engine of the vehicle on that location.

(d) Dense leaf types trees planting, such as Ashoka Tree. This type of tree will help to absorb sound level from the roadway.

\section{References}

1. J. Chaddanai, The study on noise pollution and noise barrier on highway route no. 9 (Bangkok: Kasetsart Universtiy, 2016)

2. National Environmental Board's Notification No. 15 (1997) 